\title{
COMPARISON OF PUBLISHED PROGRAM OUTCOMES WITH STUDENT AND FACULTY EXPECTED OUTCOMES USING A CONSTRUCTIVIST ALIGNMENT APPROACH
}

\author{
Peter Draus, Robert Morris University,draus@rmu.edu
}

\begin{abstract}
This study presents an analysis of published program outcomes, student expected outcomes and faculty expected outcomes for students in a D.Sc. program at a tier 1 research university. Using the constructivist alignment theory, a thematic analysis of the outcomes was conducted and a comparison of the results for each group was completed. The results showed a major disparity between the students and the published outcomes, especially in the area of personal achievement and social themes. There were smaller differences between the faculty and the students and the faculty and the published outcomes as well.
\end{abstract}

Keywords: Doctor of Science (DSc), Communications, Constructivist Alignment approach, Program Outcomes, $\mathrm{ABCD}$ approach to outcomes development, Faculty vs Student.

\section{INTRODUCTION}

When developing new education programs or when the programs are being accredited, the program outcomes or objects lists what the program plans to accomplish for its graduates. Program objectives are not only used by students to select an appropriate program but are also used to compare programs to each other (Leon 2018). It would seem appropriate that the students who choose a particular program select the program based on what they hope to get out of the program ie. the program objectives. Additionally, one would expect the outcomes of the program are congruent with the outcomes that the faculty who teach and developed the program have for their students. This study looks at the official program objectives and their expected outcomes of students and faculty in a D.Sc program at a tier 1 research institution in the United States based on a constructivist alignment approach. Some of the benefits of congruence would be; 1 ) to better align the (expensive) program with the student's desires 2) to increase the effectiveness of the instruction 3 ) to make recruitment more effective.

\section{BACKGROUND}

Learning objectives or outcomes are grouped into three broad categories; institutional objectives, program objectives and course objectives (LaCount and Jackson 2019). The institutional objectives are what students are expected to get out of their entire degree, while the program outcomes are what they are to get out of their major and the course outcomes are what they are to take away from each course. In a doctoral program which only has courses within the major, the program and institutional objectives tend to merge together. This study focuses on the program outcomes.

In their 2016 policy statement "Higher Education Quality: Why Documenting Learning Matters", the National Institute for Learning Outcomes not only stresses the need for outcomes "Virtually everyone agrees that what students learn in college is central to subsequent success and satisfaction..." but also that the faculty are key stakeholders in this process. They suggest that the individual course assignments link back to the program outcomes themselves and that "Faculty engagement and ownership are essential if assessment and improvement efforts are to be effective" (NILOA, 2016).

There is some concern that program outcomes are not a good measure of the success of the program and their graduates. Arne Duncan, when he was the Secretary of the US Department of Education had great concerns in the 
usefulness of program outcomes as a measure of the success of programs in Higher Education. (Duncan 2015) He writes, "For many accreditors, student outcomes are way down the priority list. The current system of continuous improvement is in desperate need of its own improvement." While his main concern that the accreditation bodies were not scrutinizing the universities closely enough, he clearly sees a disconnect between what the students want/need and what the university delivers when he writes, "But unfortunately for millions of other students, our higher education system isn't delivering what they need, or deserve" (Duncan 2015). This study is looking at the congruence of the outcomes between the faculty, institution and student. On the surface this may eliminate the need to worry about the usefulness of outcomes, the relative importance of the outcomes to each group may be different, so this might be an influence on the perceived differences.

LaCount and Jackson surveyed over 8500 program outcomes at 73 different higher education institutions. They found that the top 5 themes of program outcomes were: Intellectual skills; Technology; Communication; Culture; and Personal Fulfillment. (LaCount and Jackson 2019 p.25) Two of the three major findings were that "There may be misalignment between what programs do and what institutions expect" and "A campus' values may not be displayed in their outcomes as much as they think" (LaCount and Jackson 2019 p.5)

Currently there is still a fundamental conflict between the program assessment and accreditation model which stresses the use of behavioral objectives that are easily measured and the constructivist teaching model that are used by some faculty. Biggs developed the concept of "Constructive alignment" to bridge this gap at the course level.(Biggs, 2003, 2011) Typical behavioral objectives are written using the ABCD method which follows the Audience, Behavior, Condition and Degree (Kiliçkaya, 2016). The use of Blooms Taxonomy for assessment purposes allows for easy integration from the broadest institutional level outcomes to the smallest course level outcomes. In this method, objectives tend to be smaller and incremental (Lang 2016) while the goal of program objectives is to be broad in scope (Drexel 2019). Allen suggests that the alignment from course outcomes all the way to Institutional outcomes, termed a cohesive curriculum, increases student performance (Allen, 2004). The fundamental conflict between broad program and institutional outcomes and the desire for small ABCD objectives can be exemplified by the desire for all outcomes to only incorporate a single element. (Levey 2019). This works fine in small course level outcomes, but at a broader program level outcome, it is hard to encapsulate broad outcomes without incorporating multiple themes. That is why this study utilizes a thematic approach to the outcomes. The goal is not to match the outcomes one for one within each group, but to find the themes in the outcomes for each group and compare those together.

The ABCD (Kilickaya 2016) method starts with evaluating the audience, in reality the goal is to list the target audience, not take into account individual differences within the audience as would be expected in a constructivist teaching/learning model. Constructivist alignment looks at the entire student and expects learning to take place outside the classroom and at a level that is dependent on each student's desires (Kabouha, R., Elyas 2015).

Objectives written using constructive alignment are written using the following 4 steps:

1. Defining the intended learning outcomes (ILOs);

2. Choosing teaching/learning activities likely to lead to the ILOs;

3. Assessing students' actual learning outcomes to see how well they match what was intended; 4. Arriving at a final grade. (Biggs 2003)

\section{Constructivist Alignment Approach}

The Constructivist Alignment Approach as developed by Briggs, focuses on the type of learning activities used by the students. Like any of the Constructivist models, this model is based on the notion that the student "constructs" their own learning and is an active participant in the development of the learning goals, not just a participant in the learning activities as would be assumed in a cognitive model or just a passive receiver of information as in a behavioral model. The goal is to align the activities with what the student wants to get out of the instruction (Briggs, 20011). In the constructivist approach the instructor does not develop "objectives" but intended learning outcomes (ILOs).

Briggs makes it clear that the goal of writing the ILO's is to not just list a criterion level to be met, but to match the outcomes with the students' desires; he writes, "When we teach we should have a clear idea of what we want our 


\section{Issues in Information Systems}

Volume 20, Issue 2, pp. 97-104, 2019

students to learn." (Briggs, 2003 p2). Using this theory supports the matching of the student's desired outcomes with the published outcomes of the program.

Doctorate of Science - D.Sc.

The degree that was used in this study was the Doctorate of Science (D.Sc.) degree. This is in contrast to the better known Doctorate of Philosophy (Ph.D.) degree. The primary difference between the degrees is the degree of emphasis on research with the Ph.D having a greater emphasis on research and the D.Sc. having a focus on more practical applications. Even the definition of the two degrees does not reveal a clear cut difference between the two degrees. The Brainy Encyclopedia defines Sc.D. or D.Sc. as "Abbreviation of the Latin Scientific Doctor. It is an academic degree on par with the wider known Ph.D. The D.Sc. is awarded predominantly in engineering sciences, whereas classical sciences seem to prefer the Ph.D." (NationMaster, 2004). The same web site defines Ph.D. as "an abbreviation of the Latin Philosophical Doctor .... Was originally a degree granted to a learned individual who had achieved the award and who had demonstrated a long and productive career in the field of philosophy" (NationMaster, 2004). Plus, the US Department of Education and the National Science Foundation recognize both degrees as research doctorates (NationMaster, 2004).

\section{The Doctoral Program}

The Doctor of Science in Information Systems and Communications degree that was used is this study was started in 1999. The first group of students graduated from this program in May of 2002. The goal of this program as stated in the university materials is to "address the expanding needs of professionals who conduct research; manage information resources, solve information, communication, and technology-related problems in businesses and other organizations; or who educate and/or train others in applications of information systems and communications" (XUNIVERSITY, 2018). The program utilizes a cohort model in which the students move through their entire degree experience together. This includes two week long and six weekend residencies which include meals together and housing in the same location. The self-selection into such a program might have impacted some of the student's expected program outcomes.

\section{Research Questions}

This study will use a thematic analysis and reduction to develop themes form the students, program and faculty's outcomes. The research questions are based on the results of this thematic analysis and not the outcomes themselves.

RQ1. What are the major themes of the D.Sc. program?

RQ2. What are the major themes of student expectations from obtaining a D.Sc. degree?

RQ3. What are the major themes of faculty expectations for students obtaining a D.Sc. degree?

RQ4. What are the differences between the expected outcomes themes in a D.Sc. program between the students, the themes from the published outcomes and the themes from the faculty who developed the program?

\section{RESEARCH METHODOLOGY}

\section{Data Collection}

Data was collected over a three year period from 25 students in the D.Sc program. An ungraded assignment in one of the courses in the program had the students list the outcomes they expected from the program. The official expected program outcomes were published by the XUniversity. Finally, interviews were conducted with faculty to gather the expected program outcomes as part of work to revise the program. Data included three faculty who were part of the team of faculty who developed the program.

\section{Data Analysis}

A thematic analysis was conducted on the data from the students. All of their responses were initially coded and then two rounds of reduction were conducted. For the faculty interviews, each interview was reviewed and themes pulled from the transcriptions. A second review of each interview was then undertaken to ensure all themes were found. Again, two levels of reduction were undertaken to reduce the number of themes. The program outcomes were obtained, and themes developed from the published outcomes. These themes were then reduced a single time before comparison to the other themes. 


\section{Issues in Information Systems}

Volume 20, Issue 2, pp. 97-104, 2019

Finally, a comparison of the outcomes between the students, faculty and published expectation was conducted.

\section{RESULTS}

\section{Program Outcomes - RQ1}

These are the published program level outcomes for the D.Sc program at XUniversity.

1- Develop and apply skills in a range of investigative methods, including qualitative methods grounded in economic, social and ethnographic disciplines, and quantitative methods grounded in statistical and social scientific disciplines.

2- Conduct research and design innovative, effective solutions to information management and information resource problems.

3- Stimulate field-based information management initiatives that link information, communications, technology, and systems within organizations.

4- Track new information technology and assist in incorporating it into an organization's strategy, planning, and practice.

From these 4 program outcomes, the following 11 themes were developed after the thematic analysis. Table 1 shows these themes before any reduction. These themes were used as the basis for the rest of the study.

Table 1. Themes from published program outcomes.

\begin{tabular}{|rl|}
\hline \multicolumn{1}{|l|}{ Themes from Published Program Outcomes } \\
\hline 1. & Apply investigative methods \\
\hline 2. & Social and ethnographic disciplines \\
\hline 3. & Social scientific disciplines \\
\hline 4. & Qualitative analysis \\
\hline 5. & Quantitative analysis \\
\hline 6. & Grounded in statistical and social scientific methods \\
\hline 7. & Conduct research \\
\hline 8. & Solve information management problems \\
\hline 9. & Combine systems thinking and information and communications technology in solutions \\
\hline 10. & Stay abreast of current technology \\
\hline 11. & Incorporate cutting edge technology in practice \\
\hline
\end{tabular}

After two rounds of thematic reduction the reduced themes were matched with the overall four themes that were found in the study.

Table 2. Reduced themes from published program outcomes.

\begin{tabular}{|c|c|}
\hline Themes developed from the Outcomes & Counts \\
\hline 1. $\quad$ Practical & 5 \\
\hline 2. Personal achievement & 0 \\
\hline 3. Research related & 4 \\
\hline 4. Social & 0 \\
\hline
\end{tabular}

\section{Themes from students expected outcomes - RQ2}

After the first reduction pass through the student's data thirteen themes/outcomes were developed as shown in Table 3. The counts are for the number of students who mentioned this theme in their list of outcomes as what they desired from obtaining the degree. After a second reduction the number of themes were reduced to 4 , as shown in Table 4. 
Table 3. Themes from Student expectations from a DISC program.

\begin{tabular}{|l|l|l|l|}
\hline Themes developed from the Outcomes & Count & Theme & Program Outcome Match \\
\hline Conduct research & 8 & 3 & 2 \\
\hline Become expert/prestige & 8 & 4 & \\
\hline Career change/advancement/marketable & 8 & 1 & \\
\hline Personal goal (first in family) & 8 & 2 & \\
\hline Obtain degree & 7 & 1 & \\
\hline Social interaction/networking & 6 & 4 & \\
\hline Increase knowledge & 5 & 2 & 1 \\
\hline Critical thinking skills & 3 & 2 & 1 \\
\hline Publish & 3 & 3 & 2 \\
\hline Public speaking & 2 & 2 & \\
\hline Writing proficiency & 2 & 2 & \\
\hline Utilize GI bill/fringe benefit & 1 & 1 & \\
\hline
\end{tabular}

Table 4. Reduced list of themes from student expectation from a DISC program.

\begin{tabular}{|c|c|}
\hline Themes developed from the Outcomes & Counts \\
\hline 1. Practical & 16 \\
\hline 2. Personal achievement & 20 \\
\hline 3. $\quad$ Research related & 11 \\
\hline 4. Social & 14 \\
\hline
\end{tabular}

\section{Faculty results - RQ3}

The themes that were developed from the faculty interviews are shown in Table 5 below. The three faculty interviewed have been part of the program since it first started. The interviews were conducted separately, and the expected outcomes were drawn from a review of the transcripts. Similar to the other two sections, a thematic analysis was conducted on these objectives to produce the themes shown below.

Table 5. Themes developed from Faculty expectation for students in a D.Sc program.

\begin{tabular}{|rl|}
\hline \multicolumn{1}{|c|}{ Initial Faculty Themes } \\
\hline 1. & Change their view of reality \\
\hline 2. & Life changing experience \\
\hline 3. & Contribute to the research in the field \\
\hline 4. & Reconsider the aspect of "control" of a system \\
\hline 5. & Outcomes were about solving problems but have expanded to include research \\
\hline 6. & Become an objective consultant \\
\hline 7. & Take on a meta-perspective \\
\hline 8. & Research into information and communications \\
\hline 9. & Publish in the field \\
\hline 10. & Get a new job \\
\hline 11. & Changed from practical degree to a degree focused on teaching in for higher education \\
\hline
\end{tabular}

After two rounds of thematic reduction the reduced themes were matched with the overall four themes that were found in the study. The results are shown in Table 6 below. 
Table 6. Themes from reduced faculty expectation for students in a D.Scprogram.

\begin{tabular}{|c|c|}
\hline Themes developed from the Outcomes & Counts \\
\hline 1. Practical & 5 \\
\hline 2. Personal achievement & 1 \\
\hline 3. Research related & 2 \\
\hline 4. Social & 2 \\
\hline
\end{tabular}

It should be noted that all faculty mentioned that the program had shifted its focus more toward the development of higher education faculty with a greater emphasis on research and consequently less focus on practical applications in response to feedback from students and alumni of the program.

\section{Differences between the themes from the students expected and published outcome's- RQ4}

Clearly there are major differences between the student's expected outcomes for the social and personal themes and those of the published outcomes which did not have any themes in these two sections. Interestingly the ratio of themes in the research and practical sections was consistent between the students (16/11) and the published outcomes (5/4).

Additionally, the highest theme in the student group was personal achievement (20) and the lowest was research (11) while the published had zero for the personal achievement and the second highest for the research theme. This low ranking in the research theme reflects the lower emphasis that the D.Sc. program has on research than an equivalent Ph.D. program.

\section{Differences between the themes of the Students and Faculty}

The personal development theme had the greatest difference between the faculty and the students. In fact, this theme was the lowest with a single mention for the faculty and was the highest for the students (20). Yet the faculty still had personal development listed. The practical theme was the highest for the faculty (5) and was the second highest for the students. The social themes had two occurrences for the faculty while again it was the highest theme for the students (20).

\section{Differences between the themes of the Faculty and Published outcomes}

The faculty themes included both social (2) and personal achievement (1) which the published outcomes themes did not include at all. They both had practical themes as their most common theme (5/5). Surprisingly the research theme was lower for the faculty than the published outcomes theme $(2 / 4)$.

\section{Discussions}

The greatest disparity between the groups was between the student's expectations and the published outcomes. This is quite surprising if you assume that the students used the published outcomes in their selection process for a doctoral program. Clearly in this situation, that is not the case. The other major difference was the high number of social themes that the students submitted and also the lack of these same social themes being part of a both the published and faculty outcomes. For a program that is structured to provide a high level of social support and interaction and one that spends considerable resources in that pursuit, it is odd that these themes are missing. As noted earlier it is not surprising that a group of students that self-selected into such a program had such a high number of responses on the social theme.

It might be expected that the students had a high number of personal achievement themes, but what is surprising is the low number for faculty and the total lack of such themes in the published outcomes. It is possible that both the personal achievement and social outcomes were not explicitly stated by the faculty or published outcomes but as shown by the design of the program and are assumed to be there. This could be an artifact of the use of the ABCD method in the development of the published program outcomes and the faculty's familiarity with using this method in outcome discussions. There are real differences between using ILO's and behavioral objectives. It would be interesting to see how the published outcomes and faculty interviews would change if they were developed using 


\section{Issues in Information Systems}

Volume 20, Issue 2, pp. 97-104, 2019

Biggs constructivist alignment approach with ILO's instead of objectives. This approach looks more to what the student wants to get out of the educational experience.

One aspect of the themes that was observed by the researcher but was not directly related to the research questions was the timeline of the outcomes. Most of the published outcomes were of the short or medium time limit while the student outcomes were short term with the faculty outcomes having some of the longest expected outcomes timeline.

The other aspect of this research that is interesting is with the large disconnect between the published outcomes and the student outcomes. If there is such a larger difference between what the student is looking for and what the program advertises; the use of such program outcomes as a method of comparison between programs for prospective students is problematic.

\section{SUMMARY}

There were major differences between the student expected outcomes and the published outcomes and smaller differences between the student expected outcomes and faculty expected outcomes. The social and personal achievement themes for students were the most important, yet they weren' $t$ ' even mentioned in the published outcomes. It was suggested that the use of the constructivist alignment approach to the development of program outcomes may reduce this difference.

\section{Future research}

This study showed a difference between the faculty and students desired outcomes and the published expected outcomes of a doctoral program. Further study should look at the students perceived outcomes vs their expected and measured outcomes. Additionally, it would be interesting to see if these differences were as pronounced if the program objectives were written using ILO instead. This would allow us to further utilize the constructivist alignment theory as a base for the evaluation of a program meeting the goals of its students.

\section{REFERENCES}

Allen, M. (2004)Assessing Academic Programs in Higher Education. Ankor Publishing Comnpany Bolton MA.

Biggs, J and Tang, C. (2011): Teaching for Quality Learning at University, (McGraw-Hill and Open University Press, Maidenhead)

Biggs, J (2003): Aligning Teaching and Assessment to Curriculum Objectives, (Imaginative Curriculum Project, LTSN Generic Centre)

Blank, M. A. (1988). Mentoring and the process of becoming a teacher. Unpublished doctoral dissertation, University of Tennessee, Knoxville.

Bonilla, J., Pickron, C., \& Tatum, T. (1994). Peer mentoring among graduate students of color: Expanding the mentoring relationship. New Directions for Teaching and Learning, 57, 101-113.

Chan, S. (2010). Applications of andragogy in multi-disciplined teaching and learning. Journal of Adult Education, $39(2), 25-35$.

Denecke, D., Kent, J., McCarthy, M.T. (2017) Articulating learning Outcomes in Doctoral Education. Washington, DC: Council of Graduate Schools.

Dorn, S. M., Papalewis, R., \& Brown, R. (1995). Educators earning their doctorates: Doctoral student perceptions regarding cohesiveness and persistence. Education, 116(2), 306-314.

Drexel University (2019) Drexel university. https://drexel.edu/provost/assessment/outcomes/developing-program/ retrieved 5/6/2019.

Duncan, A. (2015). Toward a New Focus on Outcomes in Higher Education. US Department of Education Website Https://www.ed.gov/news/speaches/toward-new-focus-outcomes-higher-education. retrieved 5/7/2019 


\section{Issues in Information Systems}

Volume 20, Issue 2, pp. 97-104, 2019

Gill, G. and Bhattacharya, A. (June 2009). Whom are we informing? Issues and recommendations for MIS Research from an informing sciences perspective. MIS Quarterly, 33(2), 217-235.

Glaser \& Strauss (1967). The discovery of grounded theory: Strategies for qualitative research. Chicago: Aldine Publishing Company.

Kabouha, R., Elyas, T. (2015). Aligning Teaching and Assessment to Course Objectives: The Case or Preparatory year English Program at King Abdulaziz University. International Journal of Applied Linguistics \& English Literature. 4(5).

Kilickaya, F. (2016) Teaching how to write Instructional Objectives to pre-service Language teachers through the ABCD method. . In: Mark Krawiec (Ed.) New Insights into Language Teaching and Learning Practices, (p. 41-52). Regensburg: Sprachlit Verlag.

Kram, K. E. (1985). Mentoring at work: Developmental relationships in organizational life. Glenville, IL: Scott, Foresman and Co.

LaCount, S., Jackson, M. (2019). Degree of Difference: What do Learning Outcomes Say about Higher Education?" Campuslabs.

Lang, D. (2016). The Importance of Learning Objectives in Program Design and Evaluation. Center for Health Policy and Research (CHPR) Publications. 198. https://escholarship.umassmed.edu/healthpolicy_pp/198 retrieved 4/23/2019.

Leon, J. (2018) Developing a Graduate Master's Degree Program in Engineering Technology: Overview of Program Objectives, Structure \& Impact. Proceedings of the 2018 ASEE Gulf-Southwest Section Annual Conference The University of Texas at Austin April 4-6, 2018

Levey, J. (2018) A Brief Guide to Creating Learning Outcomes. http://www.presence.io/blog/a-brief-guide-towriting-learning-outcomes/ retyrieved 5/6/2019.

Maher, M. S., Ford, M. E., \& Thompson, C. M. (2004). Degree progress of women doctoral students: Factors that constrain, facilitate, and differentiate. Review of Higher Education, 27(3), 385-408.

National Institute for learning Outcomes Assessment (2016). Higher Education Quality: Why Documenting Learnng Matters. Public Affairs at the University of Illinois.

NationMaster (2004). Encyclopedia: Ph.D. http://www.nationamaster.com. Retrieved 11/15/2004.

Noonan. M. \& Ballinger, R. (2007). Peer and Faculty Mentoring in Doctoral Education: Definitions, Experiences, and Expectations. International Journal of Teaching and Learning in Higher Education, 19(3), 251-262.

O'Shaughnessy, L. (2012). 12 reasons not to get a PhD, MoneyWatch, July 10, 2012 https://www.cbsnews.com/news/12-reasons-not-to-get-a-phd/

Patterson, T. (2016). Why do so many graduate students quit? The Atlantic, July 2016, https://www.theatlantic.com/education/archive/2016/07/why-do-so-many-graduate-students-quit/490094/

XUNIVERSITY (2018). Doctoral program at a glance. Retrieved April 6, 2018, from http://www.rmu.edu

Strauss \& Corbin (1998). Basics of qualitative research techniques and procedures for developing grounded theory. London: Sage Publications. ( $\left.2^{\text {nd }} e d\right)$.

Zmeyov, S. I. (1998). Andragogy: Origins, developments and trends. International Review Education, 44(1), 103108. 